\title{
COMPACTION OF COMPOSITES, DISPERSION-STRENGTHENED BY NANOPARTICLES, BASED ON Ti-TiC SYSTEM WITH THE METHOD OF SPARK PLASMA SINTERING
}

\author{
O. M. Syzonenko ${ }^{1}$, P. Tashev ${ }^{2}$, M. S. Prystash ${ }^{1}$, A. S. Torpakov ${ }^{1}$, \\ Ye. V. Lypian $^{1}$, V. Dyakova ${ }^{2}$, M. Kandeva ${ }^{3}$, E. I. TAftai ${ }^{1}$, \\ And Y. G. Kostova ${ }^{2}$ \\ ${ }^{1}$ Institute of Pulse Processes and Technologies, \\ National Academy of Sciences of Ukraine, \\ 43-a, Bohoyavlenskyi Ave., 54018 Mykolaiv, Ukraine, \\ e-mails: sizonenko43@rambler.ru; msprystash@gmail.com; \\ e-mails:torpakov@gmail.com; lypian@ukr.net; dioo@iipt.com.ua \\ ${ }^{2}$ Institute of Metal Science, Equipment and Technologies \\ with Hydro- and Aerodynamics Centre "Acad. A. Balevski", \\ Bulgarian Academy of Sciences, \\ 67, "Shipchenski Prohod" Blvd, 1574 Sofia, Bulgaria, \\ e-mails: ptashev@ims.bas.bg; v_diakova@mail.bg; \\ e-mail: joanna_hristova@abv.bg \\ ${ }^{3}$ Technical University of Sofia, \\ 8, "St. Kliment Ohridski" Blvd, 1756 Sofia, Bulgaria, \\ e-mail: kandeva@tu-sofia.bg
}

\begin{abstract}
The impact of the regime of high voltage electric discharge treatment of initial powder mixture in kerosene and ethanol on the structure, phase composition, hardness, microhardness, wear resistance and corrosion behaviour of metal matrix composites of $\mathrm{Ti}-\mathrm{TiC}$ system consolidated by spark plasma sintering is studied. It is shown that consolidation of $\mathrm{Ti}-\mathrm{TiC}$ powder mixture after high voltage electric discharge treatment in kerosene with "point-plane" electrode system allows increasing $\mathrm{TiC}$ content in consolidated specimens from $24 \%$ to $30 \%$.

Keywords: spark plasma sintering, metal matrix composite, electric discharge, nanocarbon, electric discharge dispersion, Titanium, plasma, plasma technologies.
\end{abstract}

\footnotetext{
${ }^{*}$ Corresponding author.

DOI: 10.7546/EngSci.LVIII.21.02.07
} 


\section{INTRODUCTION}

The need for creation of new metallic materials with high levels of physicomechanical and performance characteristics, which will provide necessary reliability of products performance in extreme conditions, is an urgent task for the development of modern technologies. During the last decades development of new Metal-Matrix Composites (MMC) has become one of the popular ways of solution of the problem of creation of the new materials with increased properties among the researchers. These materials are characterized by high hardness and strength, low specific weight, high wear resistance during abrasive wear, low value of thermal expansion coefficient [1]. Such a complex of properties ensures the wide use of MMC as structural and instrumental materials in different areas of industry, including machine building, transportation and aerospace industry.

The properties of MMC are highly dependent both on its composition and production technology. As for now, most MMC are produced using methods of powder metallurgy [1-2]. Currently, most researchers consider the creation of new MMC with increased properties, based on the $\mathrm{Ti}-\mathrm{TiC}$ powder system, as a prospective research direction due to the fact that these materials are characterized by low self-cost and chemical compatibility of the matrix and dispersion-strengthening particles [1-5].

Strength, hardness and wear resistance of MMC obtained by methods of powder metallurgy are dependent both on the method of consolidation, used for their obtainment, as well as on used technology of powders preparation. An efficient technology of preparation of initial powders of metals and super-hard materials by their treatment with high voltage electric discharge in hydrocarbon liquid was developed in the Institute of Pulse Processes and Technologies of National Academy of Sciences of Ukraine [6-10].

During such treatment, particles of treated powder undergo combined impact of mechanical (shock wave, hydro flows, cavitation) and thermoelectric (discharge channel plasma, microplasma formations between particles, discharge current, which flows directly through the particles) factors, which leads to their dispersion. Under the impact of low temperature plasma hydrocarbon liquid undergoes pyrolysis, which leads to the formation of free nanocarbon particles [10]. These particles enter reactions of carbidization with treated powder, due to which disperse hardeners are not added separately to the composition of the powder mixture, but are instead formed during its High-Voltage Electrical Discharge (HVED) processing [6-10].

In order to preserve the dispersed structure and phase composition of the powder mixture in the consolidated MMC, it is advisable to use the method 
of Spark Plasma Sintering (SPS), which is characterized by relatively low time of holding at high temperature [6-7].

Unfortunately, the impact of HVED treatment regime on such important characteristics of MMC of $\mathrm{Ti}-\mathrm{TiC}$ system as hardness and wear resistance is currently not studied enough. This limits the possibilities of creating energyefficient technology of obtainment of MMC of this system. Therefore, establishing a connection between the parameters of electric discharge preparation of the powder mixture and the peculiarities of the structure formation of MMC of $\mathrm{Ti}-\mathrm{TiC}$ system is an urgent scientific task.

The goal of present paper is to study the impact of the regime of HVED treatment of initial powder mixture on the properties of $\mathrm{MMC} \mathrm{Ti-TiC} \mathrm{system}$ consolidated by spark plasma sintering.

\section{METHODOLOGY}

\subsection{Tested materials and test specimens}

Experimental studies were performed on the experimental set-up, which was described in detail in papers [6-10]. This set-up contains an original discharge chamber, which is designed in such a way that when it is filled with treated "liquid-powder" disperse system, powder is located in the area of discharge gap.

Studies were performed by experimental treatment of $\mathrm{Ti}-\mathrm{TiC}$ powder system in hydrocarbon liquid, subsequent consolidation of MMC specimens from treated powders and determination of their composition, structure and main physico-mechanical and performance characteristics using the methodologies described in papers [6-10]. For each presented experimental point, no less than 5 experiments were performed.

During the experiments, different types of electrode systems with different quantity of anode points, through which energy stored in electric capacitor is cyclically introduced in liquid as pulses, can be installed in discharge chamber. In the present paper two types of Electrode System (ES) were used, namely "point-plane" (P-P, see Fig. 1(a)) and 3-point anode-plane (3P-P, see Fig. $1(\mathrm{~b}))$. Usage of these two types of ES is justified by the fact that, as it was shown in paper [7], change of electric field configuration by using different types of ES ("point-plane" and "multipoint anode-plane") can be used to create conditions for distribution of plasma formations through all of the volume of treated powder. Plasma formations in all of the volume of treated powder promote the intensification of erosion and hydrodynamic dispersion processes 
as well as of the synthesis of chemical compounds during HVED treatment [6-10].

Oscillograms of discharge current and voltage were recorded during the studies. They were transferred to personal computer, where electric, energetic and hydrodynamic characteristics of HVED were evaluated including time dependence of electric power, mean current rise rate and the amplitude of pressure wave, according to the methodology described in papers [6-10], by using MathCAD 14 software.

SPS of treated specimens was performed on the "Gefest-10" complex, which was designed in IPPT NASU and allows consolidation of powders in graphite matrices by mechanical loading in vacuum utilizing the passage of superposition of direct and alternating $(10 \mathrm{kHz})$ currents with total amplitude of 1.1 $\mathrm{kA}$ through the powder charge under the mechanical loading up to $50 \mathrm{MPa}$ [11].

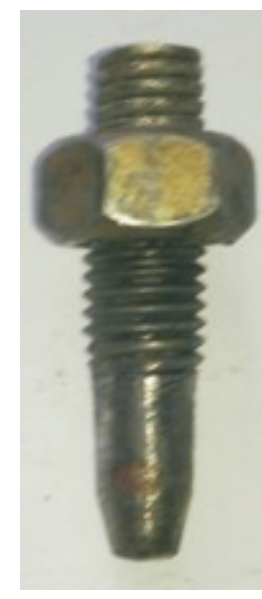

(a)

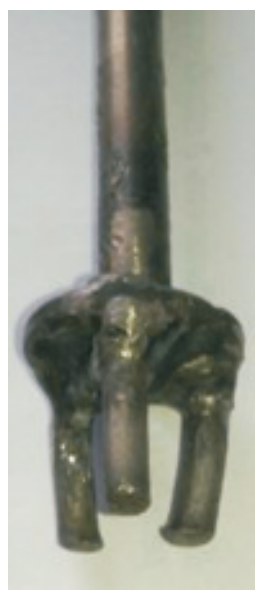

(b)

Fig. 1. Interchangeable ES anodes:

(a) point - plane; (b) 3-point anode - plane

Previous studies [6-7] have shown that in order to obtain fine material structure with notable content of $\mathrm{TiC}$ and to ensure protection of ultrafine size range (from 300 to $600 \mathrm{~nm}$ ) of $\mathrm{TiC}$ particles, the specimens heating rate during SPS has to be $10^{\circ} \mathrm{C} / \mathrm{s}$ at current rise rate of $\sim 25 \mathrm{~A} / \mathrm{s}$. Isothermal holding time at $T=1100{ }^{\circ} \mathrm{C}$ has to be no higher than 3 minutes, and the value of mechanical loading must be as high as possible (50 MPa).

Cylindrical MMC specimens with diameter about $8 \mathrm{~mm}$ and height about $5 \mathrm{~mm}$ were obtained. 


\subsection{Test methods}

\subsubsection{Microstructure observations}

The MMC structure was studied by the methods of optical and scanning electron microscopy. Metallographic sections were prepared. Macrostructure observations were performed by optical microscope BIOLAM-I, and by scanning electron microscope HIROX 5500 with EDS system BRUCKER.

\subsubsection{Hardness and wear resistance tests}

Vickers hardness was determined according to (DSTU) ISO 6507-1:2007 [6-10]. Studies of wear resistance were performed for all consolidated MMC specimens. Methodology of abrasive wear characteristics lies in the measurement of mass wear of the specimens during given friction path (number of cycles $N$ ) at constant preset dynamic regime and friction conditions: normal loading, sliding speed, type of abrasive material, specimens size.

The mass of the specimens before and after friction was measured on WPS 180/C/2 electronic weights and rounded to the closest $0.1 \mathrm{mg}$. Specimens were cleaned with a degreaser from mechanical and organic particles and dried by ethyl alcohol to prevent electrostatic effect before each measurement. Two parameters, namely wear intensity and absolute wear resistance, were calculated after measurement. The calculation was performed in the following way.

Wear intensity $i$ is determined as a ratio of mass $m$ of surface layer destructed by friction to the unit of path $S$ :

$$
i=\frac{m}{S} \text {. }
$$

Absolute wear resistance $I_{a}$ was determined as reverse wear rate and was calculated according to the following equation:

$$
I_{a}=\frac{1}{i}=\frac{S}{m} .
$$

Abrasive wear during dry abrasive friction was studied on laboratory device, which utilizes "finger-disc" kinematic scheme at flat contact. Functional scheme of this device is shown in Fig. 2. Studied specimen (finger) 1 is fixed motionless at holder 2 of loading head 8 in such a way that the front surface of the sample is in contact with the abrasive surface 3 , which is fixed motionless on the horizontal disc 4 . Disc 4 driven by electric motor 6 rotates vertically across its central axis with angular velocity $\omega=$ const. 
Normal loading $P$ is applied at the mass center of contact pad between the specimen and abrasive surface and is provided by weights using a lever system at the loading head. Path of friction is determined by number of spins according to speedometer 7 .

Specimens had cylindrical shape with diameter of $8 \mathrm{~mm}$ and height of 5 $\mathrm{mm}$. Abrasive surface 3 was impregnated with corundum $(E)$ with hardness of 9.0 by Mohs scale, which ensures the compliance to the standard demand that hardness of abrasive surface has to be at least by $60 \%$ higher than the hardness of studied material surface layer.

Studies were performed in the following conditions: load $P=4.6 \mathrm{~N}$, speed of sliding $v_{s}=0.155 \mathrm{~m} / \mathrm{s}$, rotation frequency $n_{0}=212 \mathrm{~min}^{-1}$, abrasive surface type $-\mathrm{P} 320$ corundum, ambient temperature $T=25^{\circ} \mathrm{C}$.

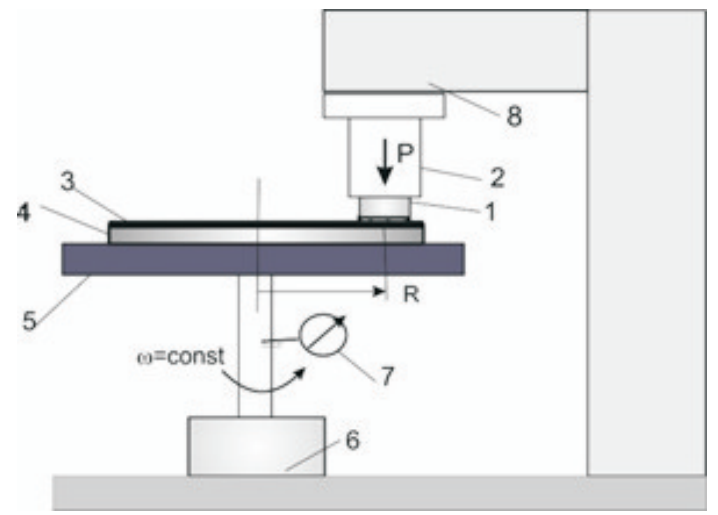

Fig. 2. Scheme of tribometer for dry friction tests on a surface with rigidly fixed abrasive particles:

1 - studied specimen (finger); 2 - holder;

3 - abrasive surface; 4 - disc; 5 - table;

6 - electric motor; 7 - speedometer

\subsubsection{Corrosion test}

The corrosion behaviour of $\mathrm{TiC}-\mathrm{Ti}$ composites was studied by accelerated model corrosion test according to ISO 11130.

The corrosion test was carried out gravimetrically by the method of periodic immersion of the specimens in environment of $3.5 \% \mathrm{NaCl}$ at temperature $21^{\circ} \mathrm{C}$ for total 1104 hours. The specimens were immersed for 247 hours in $3.5 \% \mathrm{NaCl}$ and were dried for 847 hours at $25^{\circ} \mathrm{C}$. The solution of $3.5 \% \mathrm{NaCl}$ was replaced every 168 hours. Prior the test the specimens were degreased in an organic solvent and were dried. 
After completing the test, the corrosion products were removed in ultrasound bath. The specimens were weighed prior to and after the testing on analytical scales with accuracy of $10^{-5} \mathrm{~g}$.

The mass loss index $\Delta \mathrm{m}$ was determined as $\Delta m=m_{1}-m_{0}[\mathrm{~g}]$, where $m_{1}$ was the specimen mass before the testing, and $m_{0}$ was the mass after completing the test and removing the corrosion products. The corrosion rate $K$ was calculated as $K=\Delta m / S t\left[\mathrm{~g} / \mathrm{m}^{2} \mathrm{~h}\right]$, where $S\left[\mathrm{~m}^{2}\right]$ is the surface area of the specimen, and $t[\mathrm{~h}]$ is the test duration.

\section{RESULTS AND DISCUSSION}

According to obtained values of dispersity and $\mathrm{TiC}$ concentration, powder mixtures obtained by HVED treatment of Ti powder in kerosene and ethanol with total specific energy of $W_{S}=10 \mathrm{MJ} / \mathrm{kg}$ and stored energy of single discharge of $W_{1}=1 \mathrm{~kJ}$ were selected for subsequent SPS, see Table 1.

The structure of MMC consolidated from powder mixture No. 1, see Table 1 and Fig. 3(a), is characterized by strengthening TiC particles, uniformly distributed in titanium matrix. According to the results of X-ray diffraction phase analysis, see Fig. 4(a), quantity of titanium carbide in specimens was $\sim 21 \%$.

Table 1. Powders synthesized by HVED treatment and consolidated by SPS

\begin{tabular}{|c|c|c|c|c|c|c|c|}
\hline $\begin{array}{l}\text { No. of } \\
\text { regime } \\
\text { (powder } \\
\text { mixture) }\end{array}$ & Powder & Medium & ES type & $\begin{array}{l}W_{1} \\
\mathrm{~kJ}\end{array}$ & $\begin{array}{c}W_{s} \\
\mathrm{MJ} / \mathrm{kg}\end{array}$ & $\begin{array}{c}\mathrm{TiC} \\
\%\end{array}$ & $\begin{array}{l}\text { SPS } \\
\text { regime }\end{array}$ \\
\hline 1 & \multirow{3}{*}{$\mathrm{Ti}$} & ethanol & $\mathrm{P}-\mathrm{P}$ & \multirow{3}{*}{1} & \multirow{3}{*}{10} & 19 & \multirow{3}{*}{$\begin{array}{c}T=1100{ }^{\circ} \mathrm{C} \\
\tau=180 \mathrm{~s}\end{array}$} \\
\hline 2 & & kerosene & $\mathrm{P}-\mathrm{P}$ & & & 24 & \\
\hline 3 & & kerosene & $3 \mathrm{P}-\mathrm{P}$ & & & 15 & \\
\hline
\end{tabular}

The size of strengthening nanostructured particles lies in range between $600 \mathrm{~nm}$ and $5 \mu \mathrm{m}$, but agglomerates of particles up to $50 \mu \mathrm{m}$ are also observed.

Matrix microhardness was $H_{v}=55 \mathrm{MPa}$, and microhardness of dispersion strengthening particles reaches $H_{v}=180 \mathrm{MPa}$. Vickers hardness of this material was $4.8 \mathrm{GPa}$, see Fig. 5 .

The structure of MMC consolidated from powder mixture No. 2, see Table 1 and Fig. 3(b), is characterized by agglomerates of strengthening $\mathrm{TiC}$ particles, uniformly distributed in titanium matrix. The size of $\mathrm{TiC}$ particles reaches 


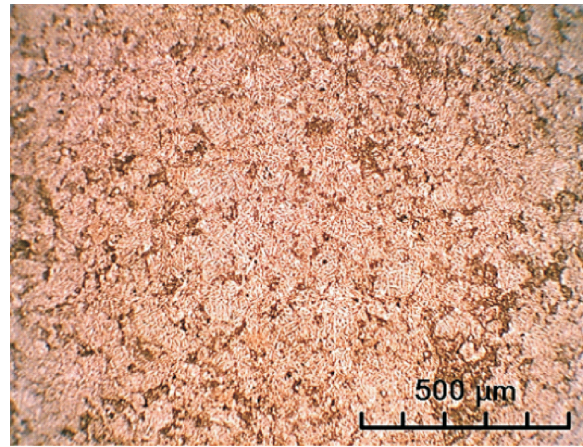

(a)

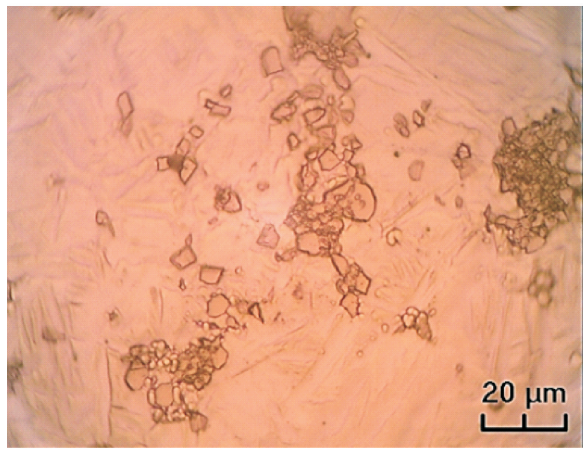

(c)

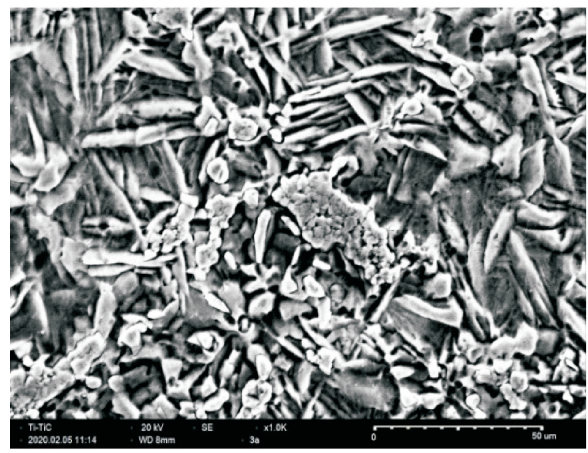

(e)

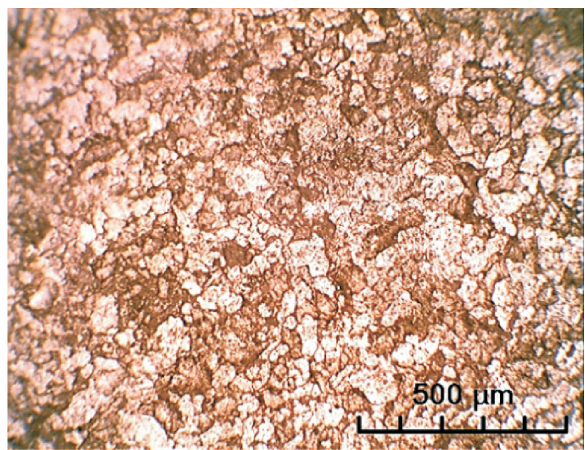

(b)

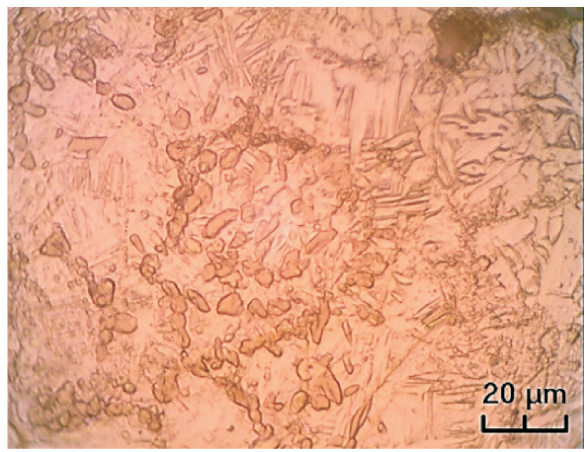

(d)

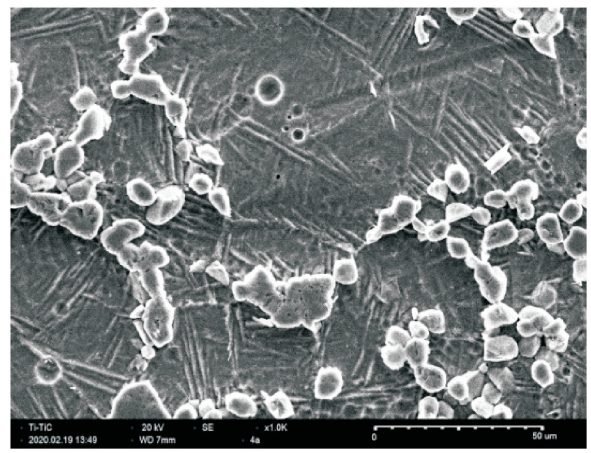

(f)

Fig. 3. Structure of Ti-TiC MMC obtained by SPS:

a, c, e - powder mixture No.1 (Table 1);

b, d, f - powder mixture No.2 (Table 1) 


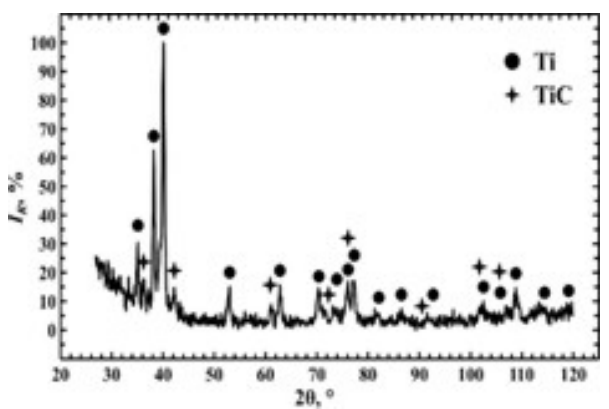

(a)

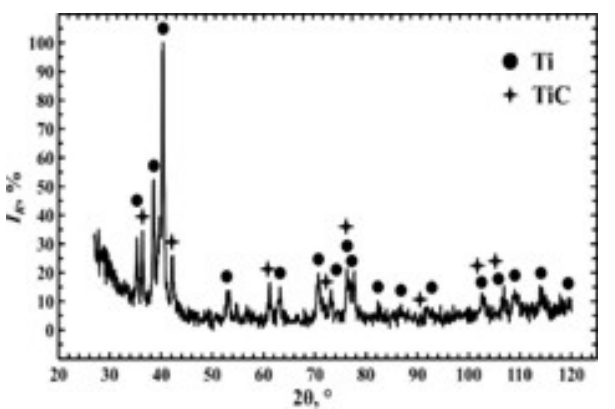

(b)

Fig. 4. Phase composition of Ti-TiC material obtained by SPS:

(a) powder mixture No.1; (b) powder mixture No.2

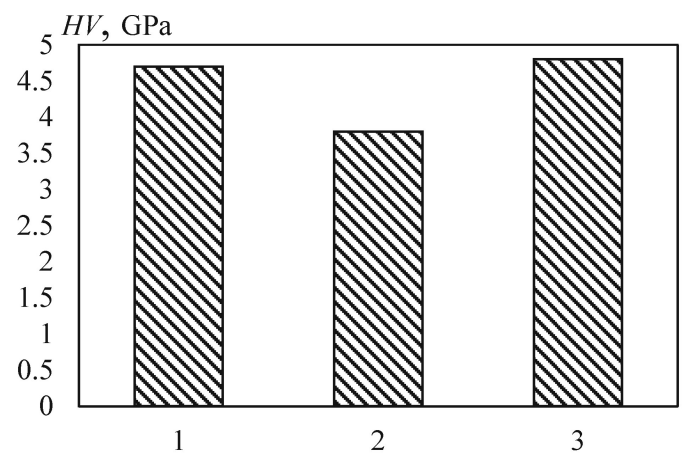

Fig. 5. Vickers hardness of Ti-TiC material obtained by SPS according to Table 1

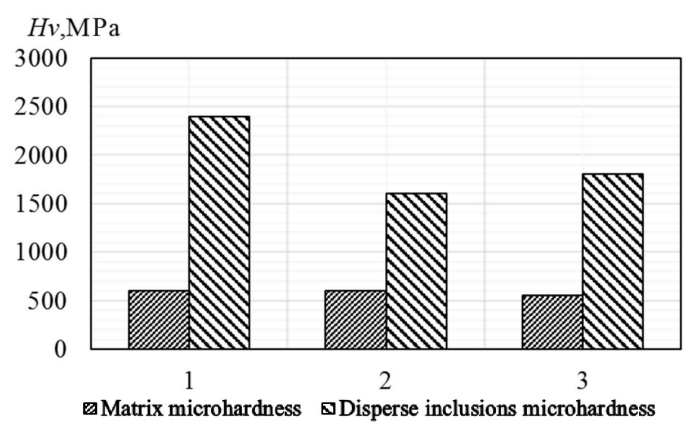

Fig. 6. Microhardness of different phases in Ti-TiC material obtained by SPS according to Table 1 
$10 \mu \mathrm{m}$ and that of the agglomerates reaches $200 \mu \mathrm{m}$. Vickers hardness of this material was $4.7 \mathrm{GPa}$, see Fig. 5. Matrix microhardness was $H_{v}=60 \mathrm{MPa}$, and microhardness of dispersion strengthening particles reaches $H_{v}=240$ MPa, see Fig. 6. Quantity of titanium carbide, see Fig. 4(b), in consolidated specimens reaches $\sim 30 \%$.

It is worth noting that MMC consolidated from powder mixture, treated in ethanol, has more uniform distribution of strengthening phase. Despite the fact that total carbide quantity in this material is lower than in case of consolidation of powder mixture, treated in kerosene in the same regime, Vickers hardness of these materials differs within the margin of error.

The structure of material consolidated from powder mixture No. 3, see Table 1 and Fig. 7, is characterized by uniform distribution of strengthening particles. Quantity of titanium carbide (see Fig. 8) in these specimens was $\sim 18 \%$. The size of individual strengthening particles rarely exceeds $5-6 \mu \mathrm{m}$, and the size of their agglomerates was around $100 \mu \mathrm{m}$. Matrix microhardness was $H_{v}=60 \mathrm{MPa}$, and microhardness of dispersion strengthening particles reaches $H_{v}=160 \mathrm{MPa}$, see Fig. 6. Vickers hardness of this material was 3.6 GPa, see. Fig. 5 .

The data on the change of titanium carbide quantity after SPS of powder mixtures is shown in Fig. 9. It should be noted that quantity of titanium carbide increases in all studied cases. Studied regimes of HVED treatment of powder mixtures No. 1, 2 and 3 ensured such conditions of HVED synthesis that almost all of synthesized carbon has bonded with titanium on the stage of electric discharge treatment of titanium powder.

Results of studies of wear resistance by method of dry friction are given in Table 2. Wear resistance of MMC obtained by SPS consolidation of powder mixture No. 1 reaches $10 \mathrm{~m} / \mathrm{mg}$. This specimen has same (within margin of error) quantity of titanium carbide both after HVED and SPS. As titanium carbide obtained during HVED and SPS has different synthesis mechanisms, it also has different properties. As noted in works [6-10], during HVED impact on solid body local overheating of material at the interface with its transition to gaseous phase takes place, which is accompanied by the synthesis and further condensation of formed compound. The size of synthesized particles in this case does not exceed several tens of nanometers. During SPS, the synthesis of carbide phases occurs due to the reaction self-propagating high temperature synthesis (SHS) between free carbon and titanium [10]. SPS process is uncontrollable, moreover, agglomerated inhomogeneous compounds with low density and low mechanical properties are the product of such kind of synthesis. The presence of agglomerated compounds with low mechanical 

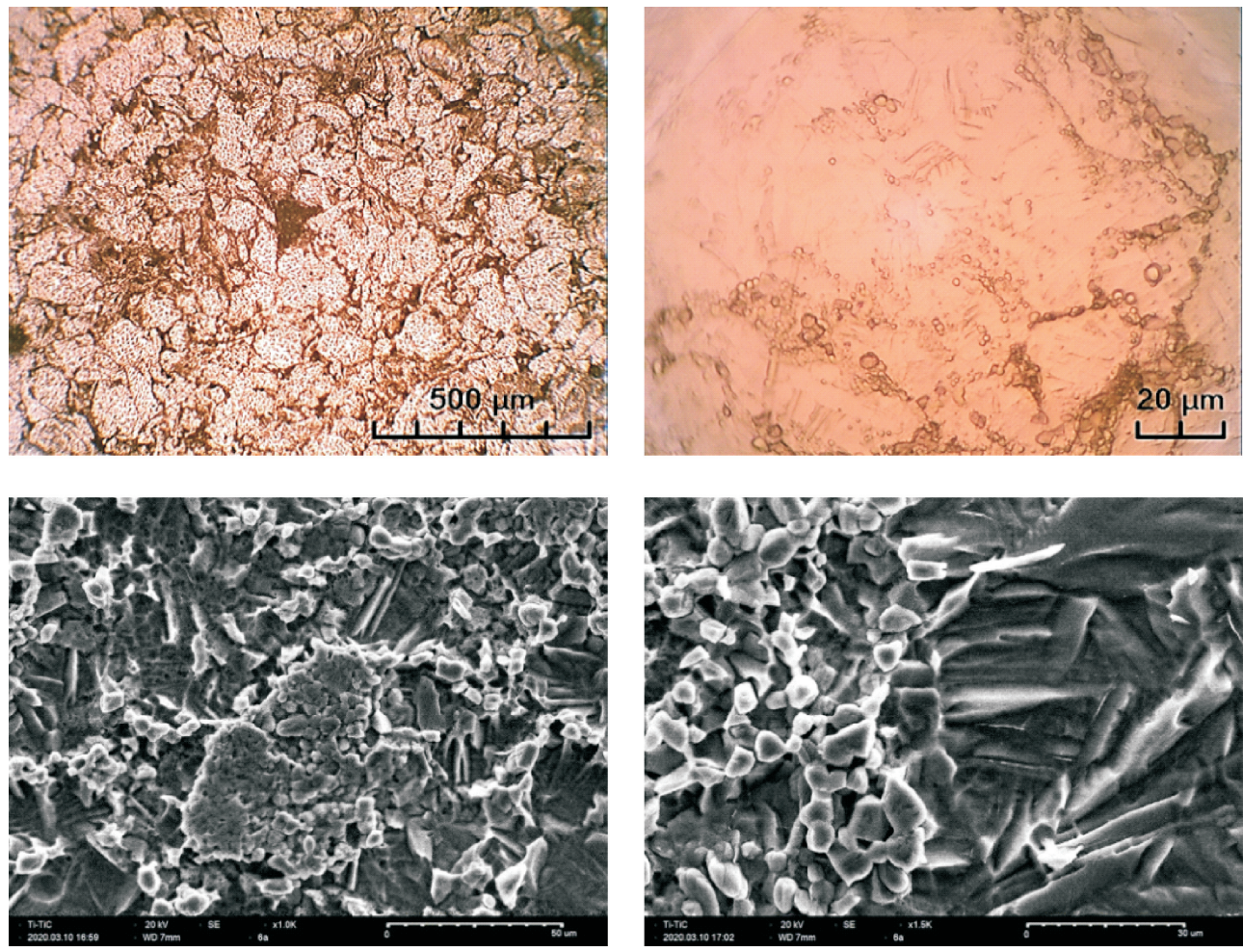

Fig. 7. Structure of Ti-TiC material obtained by SPS from powder mixture No. 3 (Table 1)

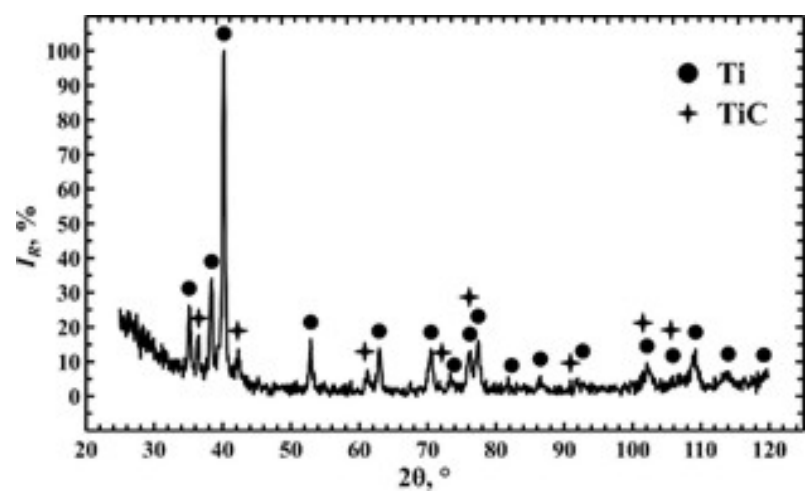

Fig. 8. Phase composition of $\mathrm{Ti}-\mathrm{TiC}$ material obtained by SPS from powder mixture No. 3 (see Table 1)

Engineering Sciences, LVIII, 2021, No. 2 
characteristics leads to the significant decrease of the levels of properties of MMC consolidated by SPS (see Table 2).

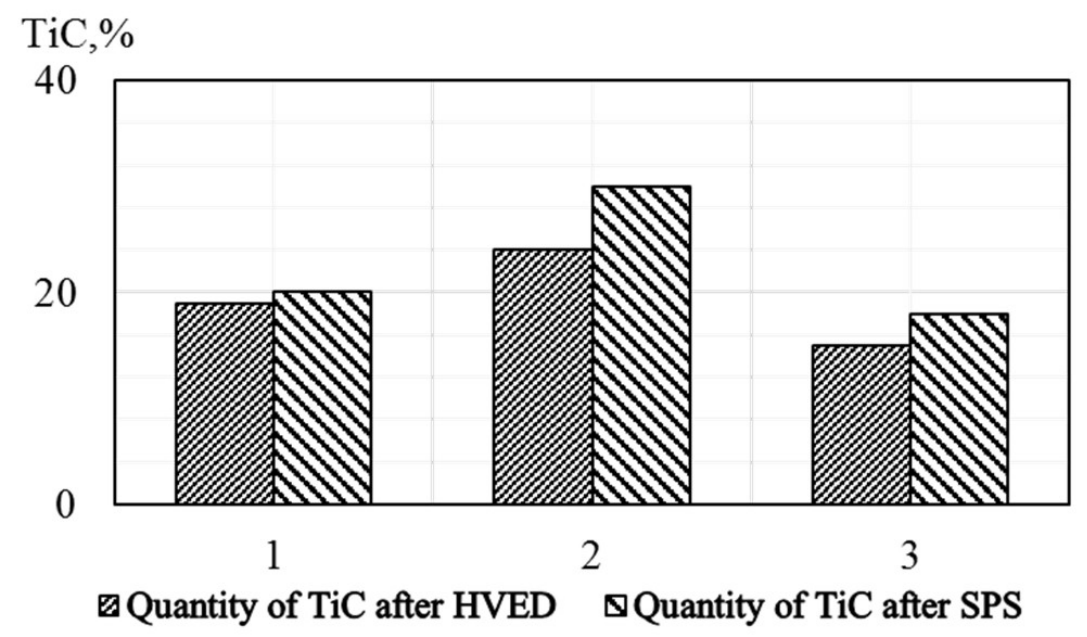

Fig. 9. Quantity of titanium carbide synthesized after HVED and after SPS of powder mixtures according to Table 1

Table 2. Wear resistance of consolidated specimens

\begin{tabular}{|c|l|c|c|c|}
\hline $\begin{array}{c}\text { No. of } \\
\text { regime }\end{array}$ & Treatment regime & $\begin{array}{c}\text { Weight } \\
\text { loss, } \mathrm{mg}\end{array}$ & $\begin{array}{c}\text { Wear rate, } \\
\mathrm{mg} / \mathrm{m}\end{array}$ & $\begin{array}{c}\text { Wear } \\
\text { resistance } \\
\mathrm{m} / \mathrm{mg}\end{array}$ \\
\hline 1 & Ethanol, ES P-P, $W_{s}=10, \mathrm{MJ} / \mathrm{kg}$ & 4.2 & 0.10 & 10.0 \\
\hline 2 & Kerosene, ES P-P, $W_{s}=10, \mathrm{MJ} / \mathrm{kg}$ & 29.3 & 0.68 & 1.46 \\
\hline 3 & Kerosene, ES 3P-P, $W_{s}=10, \mathrm{MJ} / \mathrm{kg}$ & 30.7 & 0.72 & 1.39 \\
\hline
\end{tabular}

Thus, achieving maximum efficiency of carbide synthesis on the stage of HVED treatment is a priority in order to ensure obtainment of homogeneous composite. This can be realized by variation of medium, type of electrode system and method of energy supplement. The results from corrosion resistance test are given in Table 3 .

The results of corrosion tests indicate that the corrosion rate of MMCs obtained in ethanol environment with ES P-P is higher than the corrosion rate obtained in kerosene environment with ES P-P and 3P-P. Most probably the main reason for that difference is the finer structure of the MMCs obtained under treatment mode No 1 , in which the $\mathrm{TiC}$ particles size is in the range from $600 \mathrm{~nm}$ to $5 \mu \mathrm{m}$, and the size of the agglomerates formed is about $200 \mu \mathrm{m}$, 
Table 3. Corrosion rate of the consolidated MMC specimens

\begin{tabular}{|c|c|c|}
\hline No. of regime & Treatment regime & Corrosion rate, $K\left[\mathrm{~g} / \mathrm{m}^{2} \mathrm{~h}\right]$ \\
\hline 1 & Ethanol, ES P-P, $W_{s}=10[\mathrm{MJ} / \mathrm{kg}]$ & 2.413 \\
\hline 2 & Kerosene, ES P-P, $W_{s}=10[\mathrm{MJ} / \mathrm{kg}]$ & 1.978 \\
\hline 3 & Kerosene, ES 3P-P, $W_{s}=10[\mathrm{MJ} / \mathrm{kg}]$ & 1.939 \\
\hline
\end{tabular}

thus increasing the contact surface compared to the MMCs obtained by the other two treatment modes. The MMC specimens obtained under modes No. 2 and 3 in kerosene environment with ES P-P containing 30\% TiC and 3P-P containing $18 \% \mathrm{TiC}$, respectively, show lower corrosion rate due to the larger size of $\mathrm{TiC}$ particles and agglomerates and hence the smaller contact surface with the corrosion environment.

There is evidence [12-13] that the increase of $\mathrm{TiC}$ amount in MMCs results in increased porosity, which is essential prerequisite for the development of corrosion. The mode and conditions of sintering of MMCs also affect the parameters of the microstructure, and hence the development of corrosion processes.

The mechanism of the corrosion process in the tested MMCs in $3.5 \% \mathrm{NaCl}$ can be defined as a microgalvanic cell acting at the metal/ceramic interface. The result of this impact is well illustrated in Fig. 10. The corrosion changes are manifested in uniform surface dissolution of the particles and the formed agglomerates. No local corrosion damage is observed. This type of corrosion is typical for metal matrix composites [12-15].

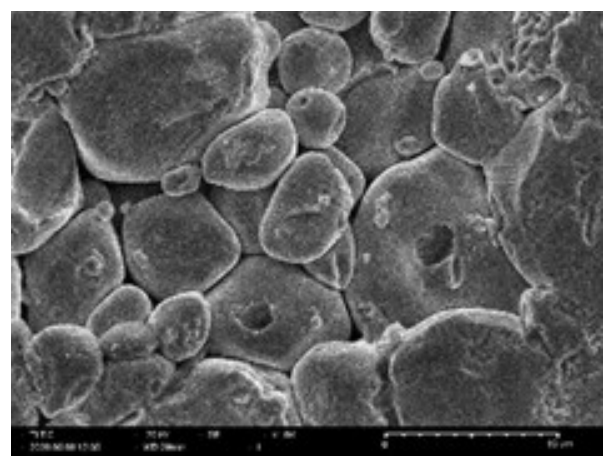

(a)

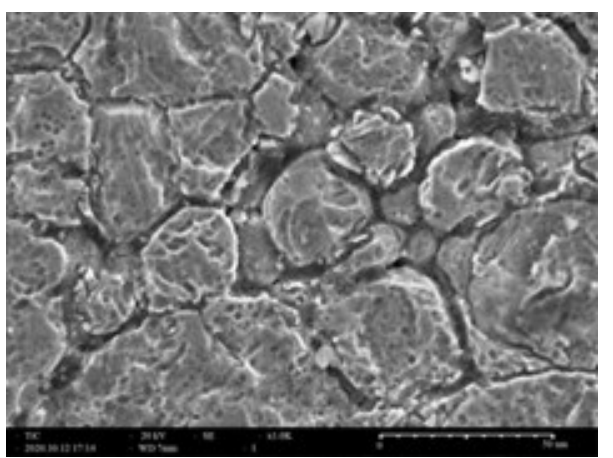

(b)

Fig. 10. Macrostructure of the of $\mathrm{Ti}-\mathrm{TiC}$ material before and after corrosion test:

(a) before corrosion test; (b) after corrosion test

Engineering Sciences, LVIII, 2021, No. 2 
Given the above results, it can be unequivocally stated that the use of $\mathrm{P}$ $\mathrm{P}$ electrode system is appropriate in the media of kerosene and ethanol with specific treatment energy up to $10 \mathrm{MJ} / \mathrm{kg}$.

\section{CONCLUSIONS}

1. Technological methods of obtaining $\mathrm{Ti}-\mathrm{TiC}$ system MMC by SPS in regime with the temperature of $T=1100^{\circ} \mathrm{C}$ and holding time of $180 \mathrm{~s}$ were developed based on the established physico-mechanical and performance characteristics of consolidated specimens.

2. It was found that consolidation of $\mathrm{Ti}-\mathrm{TiC}$ powder mixture after HVED treatment in kerosene with $\mathrm{P}-\mathrm{P}$ electrode system allows increasing $\mathrm{TiC}$ content in consolidated material from $24 \%$ to $30 \%$ in case of consolidation of $\mathrm{Ti}-\mathrm{TiC}$ powder mixture treated with specific energy of $10 \mathrm{MJ} / \mathrm{kg}$.

3. Usage of $3 \mathrm{P}-\mathrm{P}$ electrode system during treatment of $\mathrm{Ti}$ powder in kerosene does not lead to increase of $\mathrm{TiC}$ content in consolidated specimens, which indicates the absence of residual carbon after HVED treatment and allows obtaining MMC with wear resistance of $1.39 \mathrm{~m} / \mathrm{mg}$ and Vickers hardness of 3.6 GPa.

4. Consolidation of $\mathrm{Ti}-\mathrm{TiC}$ powder mixture after HVED treatment in ethanol with $\mathrm{P}-\mathrm{P}$ electrode system does not lead to change of TiC content in comparison with the treatment in kerosene in the same regime.

5. Achieving maximum efficiency of carbide synthesis on the stage of HVED treatment is a priority in order to ensure obtainment of homogeneous composite. This can be realized by variation of medium, type of electrode system and method of energy supplement.

6. The MMC specimens of powder mixture $\mathrm{Ti}-\mathrm{TiC}$ treated in ethanol with electrode system $\mathrm{P}-\mathrm{P}$ have lower corrosion resistance than the $\mathrm{MMC}$ specimens treated in kerosene under similar conditions.

\section{REFERENCES}

[1] Daulat Kumar Sharma, Devang Mahant, and Gautam Upadhyay, Manufacturing of Metal Matrix Composites: A State of Review, Materials Today, in: Proceedings, 2020, 26, Part 2, pp. 506-519.

[2] Jérôme Roger, Bruno Gardiola, Jérôme Andrieux, Jean-Claude Viala, and Olivier Dezellus, Synthesis of Ti Matrix Composites Reinforced with TiC Particles: Thermodynamic Equilibrium and Change in Microstructure, Journal of Materials Science (2017) 52 4129-4141. 
[3] D. B. Miracle, Metal Matrix Composites - from Science to Technological Significance, Composites Science and Technology (2005) 65 2526-2540. DOI: 10.1016/j.compscitech.2005.05.027.

[4] Pilli Jaya Teja, Satya Ranjan Shial, Debasis Chaira, and Manoj MasANTA, Development and Characterization of Ti-TiC Composites by Powder Metallurgy Route Using Recycled Machined Ti Chips, Materials Today, in: Proceedings, 2020, 26, Part 2, pp. 3292-3296.

[5] Shufeng Li, Bin Sun, Hisashi Imai, and Katsuyoshi Kondoh, Powder Metallurgy Ti-TiC Metal Matrix Composites Prepared by In-Situ Reactive Processing of Ti-VGCFs System, Carbon (2013) 61 216-228.

[6] O. Sizonenko, S. Prokhorenko, A. Torpakov, D. Żak, Y. Lypian, R. Wojnarowska-Nowak, J. Polit, and E. M. Sheregir, The metal-matrix composites reinforced by the fullerenes, IP Advances (2018) 8 (8) 085317.

[7] O. N. Sizonenko, E. G. Grigoryev, N. S. Pristash, A. D. Zaichenko, A. S. Torpakov, Ye. V. Lypian, V. A. Tregub, A. G. Zholnin, A. V. Yudin, And A. A. Kovalenko, Plasma Methods of Obtainment of Multifunctional Composite Materials, Dispersion-Hardened by Nanoparticles, High Temperature Materials and Processes (2017) 36 (9) 891-896.

[8] O. N. Sizonenko, N. A. Oleinik, G. A. Petasyuk, G. D. Il’nitskaya, G. A. Bazalii, V. S. Shamraeva, Éi. Taftai, A. S. Torpakov, A. D. Zaichenko, And E. V. Lipyan, Effect of High-Voltage Electrical Discharge Treatment of Diamond Powders on Their Mechanical Characteristics, Powder Metallurgy and Metal Ceramics (2013) 52 (7-8) 365-369.

[9] O. M. Syzonenko, P. I. Loboda, A. D. Zaichenko, Ye. V. Solodkiy, A. S. Torpkov, M. S. Prystash, and V. O. Trenub, The influence of highvoltage electrical discharge on dispersion and structure of B4C powder, Journal of Superhard Materials (2017) 39 (4) 243-250.

[10] N. I. Kuskova, O. M. Syzonenko, and A. S. Torpakov, Electric Discharge Method of Synthesis of Carbon and Metal-Carbon Nanomaterials, High Temperature Materials and Processes (2020) 39 (1) 357-367.

[11] O. M. Syzonenko, A. I. Ivliev, O. I. Raichenko, et al., Patent 101575 Ukraine, MPC B22F 3/14, B22F 3/105, B30B 15/02. Device for Spark Plasma Sintering of Powders, No. 201200957, Filed 30.01.2012, Bulletin 7, Published 10.04.2013.

[12] Zhila Memarrashidi, The Aqueous Corrosion Response of Ti $(C, N)$, TiC and WC Based Ceramic-Metal Composites, Ph. D. Thesis, Halifax, Nova Scotia, May 2015.

[13] L. Tотн, Transition Metal Carbides and Nitrides, Elsevier (2014).

[14] Y. Yang, D. Zhang, W. Yan, And Y. Zheng, Microstructure and Wear Properties of TiCN/Ti Coatings on Titanium Alloy by Laser Cladding, Optics and Lasers in Engineering (2010) 48 (1) 119-124, DOI:10.1016/j.optlaseng.2009.08.003. 
[15] D. E. Alman and J. A. Hawk, The Abrasive Wear of Sintered Titanium Matrix-Ceramic Particle Reinforced Composites, Wear (1999) 225-229, 629-639.

Received April 07, 2021 